\title{
Ultra-stiff large-area carpets of carbon nanotubes
}

Seyyed Shayan Meysami ${ }^{*}$, Panagiotis Dallas ${ }^{1}$, Jude Britton ${ }^{1 \dagger}$, Juan G Lozano ${ }^{1}$, Adrian T Murdock $^{1 \ddagger}$, Claudio Ferraro ${ }^{2}$, Eduardo Saiz Gutierrez ${ }^{2}$, Niek Rijnveld ${ }^{3}$, Philip Holdway ${ }^{4}$, Kyriakos Porfyrakis $^{1}$, Nicole Grobert ${ }^{1 \S}$

${ }^{1}$ Department of Materials, University of Oxford, Parks Road, Oxford OX1 3PH, United Kingdom.

${ }^{2}$ Imperial College London, South Kensington Campus, London SW7 2AZ, United Kingdom.

${ }^{3}$ Optics11, De Boelelaan 1081, 1081 HV Amsterdam, the Netherlands.

${ }^{4}$ Oxford Materials Characterisation Service, Oxford University Begbroke Science Park, Yarnton, OX5

IPF, United Kingdom.

\begin{abstract}
Herewith, we report the influence of post-synthesis heat treatment $\left(\leq 2350{ }^{\circ} \mathrm{C}\right.$ and plasma temperatures) on the crystal structure, defect density, purity, alignment and dispersibility of free-standing large-area (several $\mathrm{cm}^{2}$ ) carpets of ultra-long (several $\mathrm{mm}$ ) vertically aligned multi-wall carbon nanotubes (VA-MWCNTs). VA-MWCNTs were produced in large quantities (20-30 g/batch) using a semi-scaled-up aerosol-assisted chemical vapour deposition (AACVD) setup. Electron and X-ray diffraction showed that the heat treatment at $2350{ }^{\circ} \mathrm{C}$ under inert atmosphere purifies, removes residual catalyst particles, and partially aligns adjacent single crystals (crystallites) in polycrystalline MWCNTs. The purification and improvement in the crystallites alignment within the MWCNTs resulted in reduced dispersibility of the VA-MWCNTs in liquid media. High-resolution microscopy revealed that the crystallinity is improved in scales of few tens of nanometres while the point defects remain largely unaffected. The heat treatment also had a marked benefit on the mechanical

\footnotetext{
* Corresponding author. Tel: +44 1865 283730; Email: shayan.meysami@ materials.ox.ac.uk

${ }^{\dagger}$ Currently at Renishaw UK.

$¥$ Currently at CSIRO Australia.

$\S$ Corresponding author. Tel: +44 1865 283720; Email: nicole.gorbert@materials.ox.ac.uk
} 
properties of the carpets. For the first time, we report compression moduli as high as 120 MPa for VA-MWCNT carpets, i.e. an order of magnitude higher than previously reported figures. The application of higher temperatures (arc-discharge plasma, $\geq 4000{ }^{\circ} \mathrm{C}$ ) resulted in the formation of a novel graphite-matrix composite reinforced with CVD and arc-dischargelike carbon nanotubes.

\section{Introduction}

Due to their unique anisotropic properties, vertically aligned carpets of multi-wall carbon nanotubes (VA-MWCNTs) are being investigated for a variety of applications such as composites ${ }^{1-4}$, membranes and filters ${ }^{5-8}$, thermal interface materials ${ }^{9-11}$, electronic devices 12 and supercapacitors ${ }^{13-16}$. In most of these applications, high structural uniformity, low crystallographic imperfections, high purity and alignment of MWCNTs are sought after in order to achieve improved reinforcement, high electrical and thermal conductivity, etc. Despite intense research on optimising chemical vapour deposition (CVD) techniques, due to its relatively low cost, versatility, scalability, and efficiency, for the production of highquality VA-MWCNT carpets, the mechanical properties of individual CVD nanotubes ${ }^{17}$ are still inferior to the relatively defect-free arc-discharge MWCNTs. For instance, the Young's modulus of arc-discharge MWCNTs was reported to be around $1 \mathrm{TPa}{ }^{18-20}$, compared to the broad range Young's moduli measured for CVD MWCNTs (10-100 GPa ${ }^{21}$ and 50-350 GPa 18,22). For applications such as MWCNT-reinforced composites, a number of reinforcement mechanisms are proposed including matrix toughening ${ }^{23,24}$ through bridging and deflecting crack propagation and nanotube pull-out mechanism on the fracture surface ${ }^{25}$. Since the potency of such reinforcements strongly depends upon the catalyst content, purity, and defect density of the reinforcing CNTs ${ }^{26}$, maximising the crystallinity and purity of CVD MWCNTs are of prime importance. The quality of MWCNTs could be substantially improved by optimising the CVD conditions ${ }^{27-30}$ or post-synthesis heat treatments ${ }^{31-36}$. 
Previous reports ${ }^{33-35,37}$ suggest that at temperatures beyond $2000{ }^{\circ} \mathrm{C}, \mathrm{CVD}$ MWCNTs are purified, residual catalyst particles are removed, and the samples exhibit more intense characteristic (002) X-ray diffraction (XRD) and Raman G and 2D peaks. However, since high-temperature $\left(\geq 2000{ }^{\circ} \mathrm{C}\right.$ ) processing of MWCNTs supported on common CVD substrates such as alumina, silicon and quartz could melt the substrate, the MWCNT powder is often collected off the CVD substrates and placed into annealing crucible. This transfer disturbs the original on-substrate alignment of MWCNTs which means that even if the annealing treatments improve any aspect of the MWCNTs, exploitation of the asymmetric nature of the VA-MWCNTs in a target application is not an option anymore. In contrast, VAMWCNT carpets are often rigid enough and easily removable from the CVD substrates, if the thickness of the carpet is at least in the millimetre range ${ }^{30,38-42}$. VA-MWCNT carpets of such thickness can be easily handled, treated, and still retain their original alignment. Considering the recent advancements in cost-effective synthesis of large-area $\left(90 \mathrm{~cm}^{2}{ }^{30}\right.$ or up to c.a. 700 $\mathrm{cm}^{2}{ }^{43,44}$ ) carpets of ultra-long MWCNTs, evaluation of the effectiveness of post-synthesis heat treatment on the bulk properties of these relatively new macroscopic morphologies of MWCNTs seems essential. The work by Fujisawa et al. ${ }^{32}$ highlights the effect of annealing on a bulk property of MWCNTs, e.g., their volume resistivity and their work is complementary to the aforementioned classic reports on the effect of annealing on structural properties (crystallinity, purity, etc.). Moreover, although prolonging the deposition time yields thicker carpets, the purity and crystallinity of individual tubes are reported to decrease during the course of CVD ${ }^{29,30}$. Hence, the post-synthesis treatments on large-area carpets of ultra-long MWCNTs, which are generally of lower quality compared to short powder-like MWCNTs produced by means of CVD, appears even more crucial to study.

In this work, we investigated the effect of heat treatment $\left(2350{ }^{\circ} \mathrm{C}\right.$ in argon atmosphere) on the properties of free-standing large-area $\left(\mathrm{few} \mathrm{cm}^{2}\right.$ ) carpets of ultra-long (few $\mathrm{mm}$ ) VA- 
MWCNT such as self-integrity (the ability to remain intact), alignment, crystallinity, defect density, oxidation resistance, purity, dispersibility and bulk mechanical properties. In addition, we also exposed VA-MWCNT carpets directly to very high temperatures and helium-carbon plasma in order to study their behaviour under extreme arc-discharge temperatures.

\section{Experimental}

VA-MWCNT carpets were produced using a semi-scaled-up ${ }^{30}$ aerosol-assisted chemical vapour deposition (AACVD) setup reported previously ${ }^{27-30,45}$. Subsequently, the VAMWCNT carpets (thickness: $2-3 \mathrm{~mm}^{30}$ ) were peeled off from a $10 \mathrm{~cm}$ by $9 \mathrm{~cm}$ silicon substrate for further post-synthesis treatment and characterisation (figure 1).

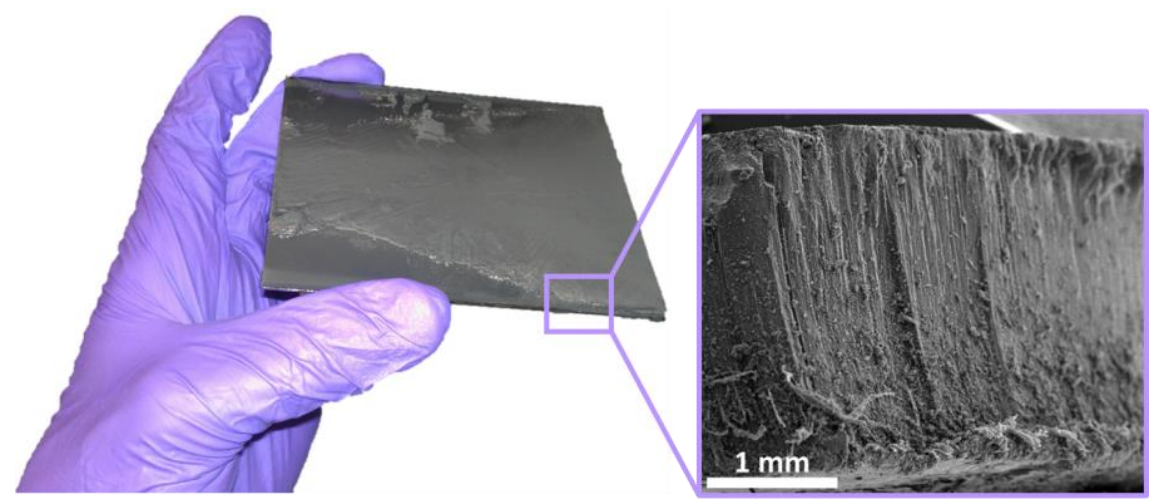

Figure 1. Free-standing VA-MWCNT carpet.

The heat treatment was carried out using a hot press (FCT Systeme GmbH) under constant 30.0 mbar 10\% helium / 90\% argon atmosphere without applied pressure. The samples were heated at $20{ }^{\circ} \mathrm{C} / \mathrm{min}$ up to $2350^{\circ} \mathrm{C}$, and kept for 3 hours before cooling down. The compression moduli of samples were measured using a cantilever based nanoindenter (Piuma Nanoindenter by Optics11), with a spherical indentation tip of $72 \mu \mathrm{m}$. The nanoindenter uses fibre-based optical interferometry to measure the indentation force and displacement at nanometre level. Indentation depth was $5 \mu \mathrm{m}$ for 'shallow' indentation and $15 \mu \mathrm{m}$ for 'deep' indentation, with a maximum indentation velocity of $6.7 \mu \mathrm{m} / \mathrm{s}$. Compression moduli of 
samples was estimated from the load-indentation curves using the Oliver and Pharr method ${ }^{46}$, where the slope was estimated between $65 \%$ and $85 \%$ of maximum load. The plasma treatment was performed in an arc discharge reactor. The starting vacuum was $3 \times 10^{-4}$ Torr and the chamber was subsequently filled with helium to a pressure of 50 mbar ensuring minimum presence of oxygen. Graphite rods supplied by Poco Graphite were used as the anode. The carpets were then wedged in a slit in the anode as shown in figure SI1 (supplementary information), so that some MWCNTs are in contact with the anode, and some are suspended. The arc took place between the carpets and a robust graphite electrode. The conditions of the annealing were 200 A DC current and $20 \mathrm{~s}$ of arc discharge, repeated 3 times.

Scanning electron microscopy (SEM), high-resolution transmission electron microscopy (HRTEM), selected area electron diffraction (SAED), Raman, thermogravimetric analyser (TGA), XRD and X-ray photoelectron spectroscopy (XPS) were used to study the structural properties of MWCNT samples (for details see the supplementary information).

\section{Results and discussions}

\subsection{Heat treatment of large-area carpets of ultra-long MWCNTs}

Figure 2 depicts the microstructure of the carpets before (a-c) and after (d-f) the heat treatment. Comparing the micrographs $\mathbf{a}$ and $\mathbf{d}$ in figure 2 reveals that at scales of around 100 $\mu \mathrm{m}$, the alignment of MWCNTs in the heat-treated carpets is improved. This can be ascertained from the majority of individual MWCNTs remaining straight and parallel to the direction of growth over few-tens-of-microns lengths. In contrast, the local arrangement of MWCNTs in sub-micron scales was not hugely altered as shown in micrographs $\mathbf{e}$ and $\mathbf{f}$ (to be compared with $\mathbf{b}$ and $\mathbf{c}$ respectively). 

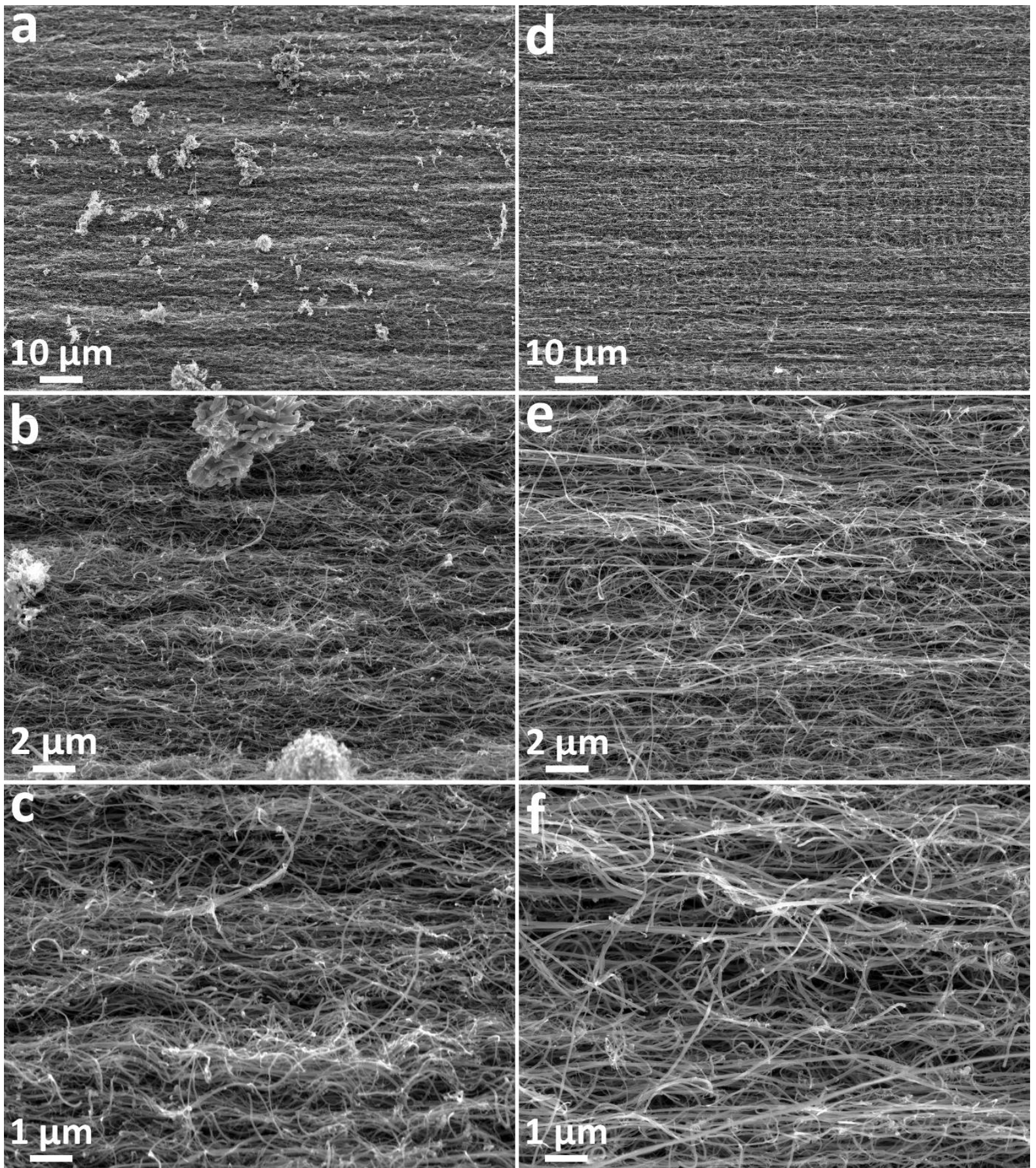

Figure 2. Scanning electron micrographs of the middle section of pristine $(\boldsymbol{a}, \boldsymbol{b}$ and $\boldsymbol{c})$ and heat-treated $(\boldsymbol{d}, \boldsymbol{e}$ and $\boldsymbol{f})$ carpets of VA-MWCNTs.

It is noteworthy that the MWCNT bundles within both the pristine and heat-treated carpets were generally more compact and aligned at the roots compared to the tips (see figure SI2). Therefore, the middle section of the carpets was used in SEM study. Comparing the TEM micrographs a and $\mathbf{d}$ in figure 3 shows that at scales of around $100 \mathrm{~nm}$, the internal structure 
of individual tubes in the heat-treated carpets exhibit less morphological distortions (bending, wall rupture, non-tubular graphitic particles, etc.), suggesting an overall enhancement of crystallinity. However, at scales of a few nanometres (compare micrographs $\mathbf{b}$ and $\mathbf{e}$ in figure 3), the arrangement of atoms in the lattice appeared unchanged. This implies that although the MWCNT crystallites have been partially annealed and aligned, full re-crystallisation of this type of CVD-grown MWCNTs is probably not achievable at these temperatures $\left(2350{ }^{\circ} \mathrm{C}\right)$. 


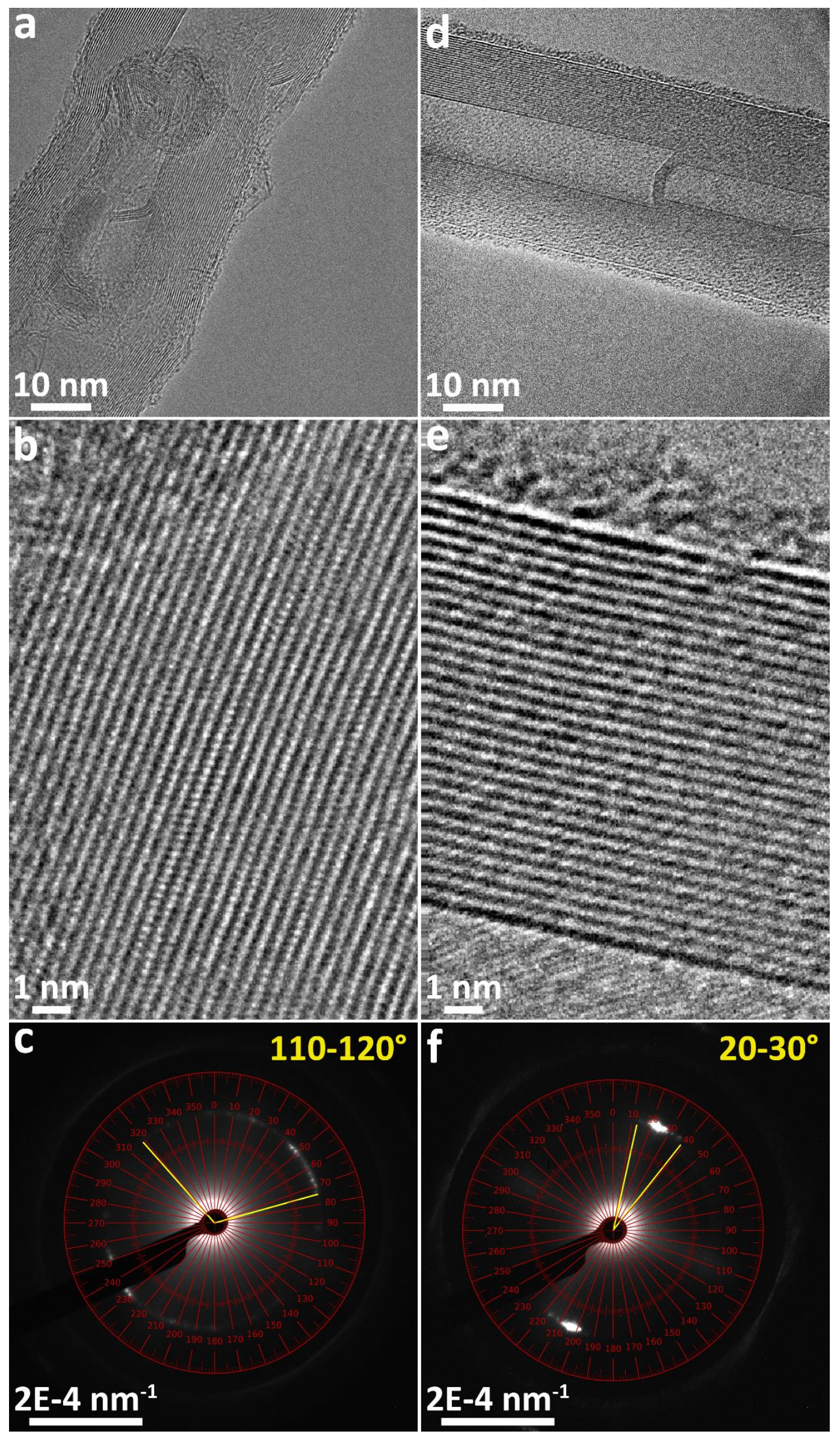


Figure 3. Transmission electron micrographs of pristine ( $\boldsymbol{a}$ and $\boldsymbol{b})$ and heat-treated ( $\boldsymbol{d}$ and $\boldsymbol{e})$ individual MWCNTs. Representative diffraction patterns of individual pristine (c) and heattreated $(\boldsymbol{f})$ MWCNTs.

This observation is in good agreement with the extensive studies of Franklin ${ }^{47,48}$ who argued that graphitisation and growth of crystallites in graphitic materials are strongly dependant on the relative initial orientations of neighbouring crystallites, and further graphitisation predominantly occurs by rearrangement of graphitic layers rather than movement of individual atoms. Here, we can similarly reason that despite the partial alignment and enlargement of MWCNT crystallites, the severe misalignment of crystallites which originated from the uncontrolled phenomena involved during the CVD requires a much higher energy/annealing temperatures to overcome. The original size of crystallites in CNTs during the synthesis could not be controlled neither, as their formation mechanism is fundamentally different from other $\mathrm{sp}^{2}$ allotropes of carbon. For instance, unlike the case of CVD graphene, in which the size or morphology of crystallites (grains) can be controlled by the number of nucleation sites ${ }^{49-52}$, crystallographic orientation of the underlying catalyst ${ }^{53}$ and time ${ }^{52,54,55}$, the crystallites in MWCNTs are likely to originate from the dynamics of the catalyst particles, as shown in a number of in situ microscopy studies ${ }^{56-60}$. As the catalyst particles deform and/or change directions (in the case of tip-growth mechanism), new crystallites are born which are not necessarily in line with the preceding one(s). In order to avoid this, one might propose that new catalyst particles which are immobilised and do not exhibit constant deformation at temperatures below $1000{ }^{\circ} \mathrm{C}$, yet showing good catalytic activities for CVD of MWCNTs should be engineered in future.

Our microscopy observations are supported by a set of systemic comparisons of electron (local) and X-ray (bulk) diffraction patterns obtained from pristine and heat-treated carpets which are presented later in this section. The spacing between the atomic planes in the walls 
of the pristine and heat-treated MWCNTs remained unchanged, certifying that the stacking of the graphitic layers is stress-free and fully relaxed even in pristine conditions.

Comparison of SAED patterns of isolated individual pristine and heat-treated MWCNTs conclusively revealed that the heat treatment reduces the polycrystallinity of the MWCNTs. Random misorientations between different crystallites in MWCNTs results in arc-shaped (002) reflections in SAED patterns. Hence, measurements of the spot arc angle in the SAED patterns of untreated and heat-treated MWCNTs will provide an indication of the improvement of the crystalline quality after heat treatment. Examples are shown in Figure 3c and $3 \mathbf{f}$ and SI3. After removing the contribution of possible local tilts of the MWCNTs in the selected area for diffraction to the overall arc angle, it was concluded that there is a $60 \%$ improvement on average of the crystalline quality after the heat treatment, even though the standard deviation is large. As discussed earlier, the alignment of individual domains in the structure of MWCNTs which exhibit monocrystallinity is believed to be more energetically favoured than recrystallisation, and hence, is more probable. This local characterisation was supported by comparing the XRD patterns of bulk pristine and heat-treated carpets (figure 4). Both samples exhibited a sharp distinguishable (002) peak at around $26^{\circ}$, indicative of graphitic structure. The doubled intensity and $20 \%$ decrease in the full width at half maximum (FWHM) of the (002) peak confirmed improved crystallinity and increase in the size of crystallites in the heat-treated sample. The (100) and (004) peaks were also more pronounced in heat-treated samples while the elimination of the peaks associated to the residual catalyst particles (carbides and oxides ${ }^{33,34}$, marked with asterisks) suggested purification of samples. Our SEM study (figure 2) and TGA results (figure 5a and $5 \mathbf{b}$ ). Confirmed the purification. 


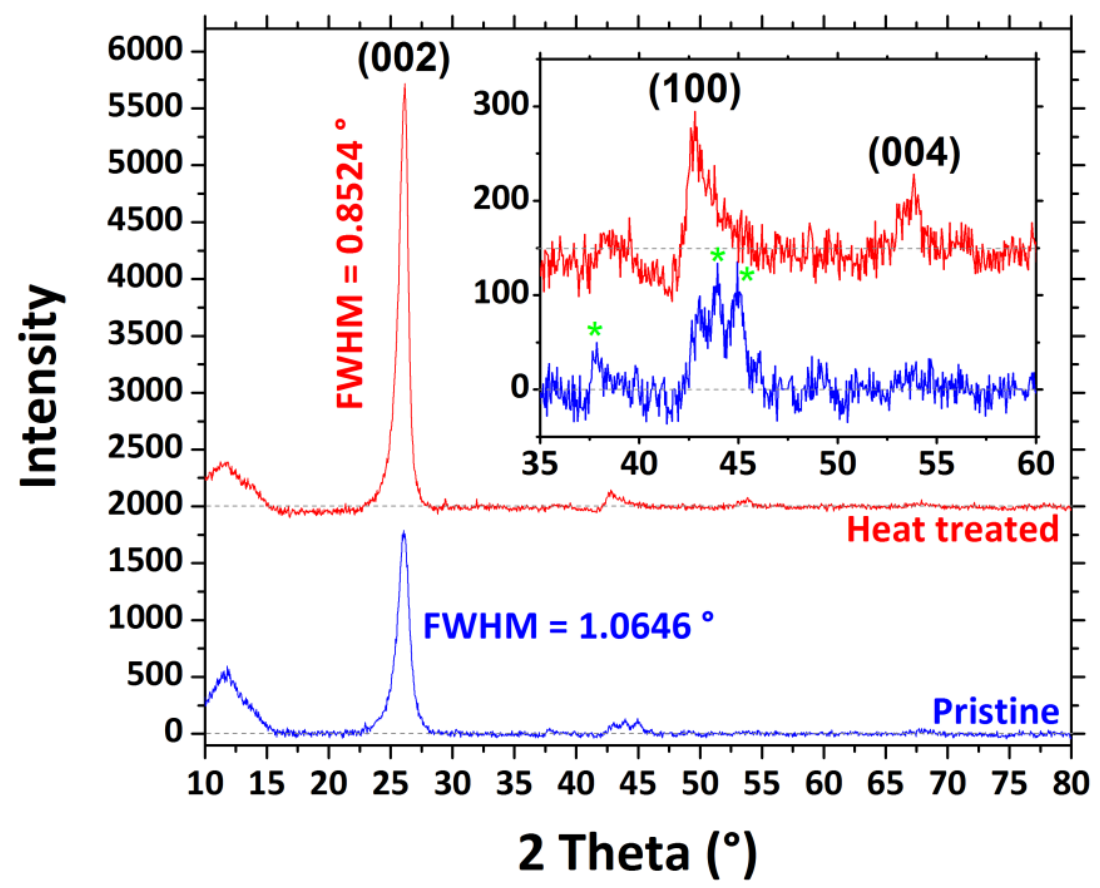

Figure 4. X-ray diffraction patterns of pristine and heat-treated carpets of VA-MWCNTs.

The heat treatment substantially improved the resistance of MWCNTs to oxidation in synthetic air. The temperatures of $20 \%, 50 \%$, and $70 \%$ mass loss were all increased by $c a$. $200{ }^{\circ} \mathrm{C}$, while the maximum rate of mass loss was halved from -1.37 to $-0.68 \mathrm{wt} . \% /{ }^{\circ} \mathrm{C}$. The improvement of oxidation resistance is believed to be mainly due to the decreased concentration of residual iron-containing catalyst particles $[29,30]$ (concentration of iron before heat treatment: 2.0 wt. $\%$; after heat treatment: 0.3 wt. $\%$ ). The increased oxidation resistance of carpets probably has little to do with the defect density because, contrary to a similar study ${ }^{37}$, our Raman results showed insignificant change in the D-band/G-band and 2D-band/G-band ratios (figure 5c and 5d and SI4). We observed 20\% decrease in the Dband/G-band ratio in the Raman spectra taken from the bottom of the carpets. Since the heat treatment effectively removes the catalyst particles and the carpets were synthesised in a bottom-growth fashion, this decrease is probably associated with the removal of the catalyst particles. The Raman D-band/G-band ratio of the core of the carpets were fairly positiondependant, but in average increased by around 0.2 after the treatment. The Raman 2D- 
band/G-band ratios for pristine and treated samples did not change substantially except for the core of the carpets, in which the 2D-band/G-band ratio decreased by around 0.14 . The origin of this decrease in the average Raman 2D-band/G-band and increase of the average Dband/G-band after the heat treatment is not fully understood yet, but given the relatively large uncertainty of the data and high sensitivity to the positions from which the spectra where taken, strong trends where not evident. Therefore, the annealing appears to be more effective in partial alignment of the crystallites of MWCNTs rather than healing the atomic-level defects. Due to the presence of relatively long and consequently heavily entangled MWCNTs in the carpets, dispersion of the samples could not be achieved and the carpets remained intact even after an hour of sonication using ultrasonic horn. Therefore, we were unable to drop-cast the samples and acquire average Raman spectra, representing the whole samples.

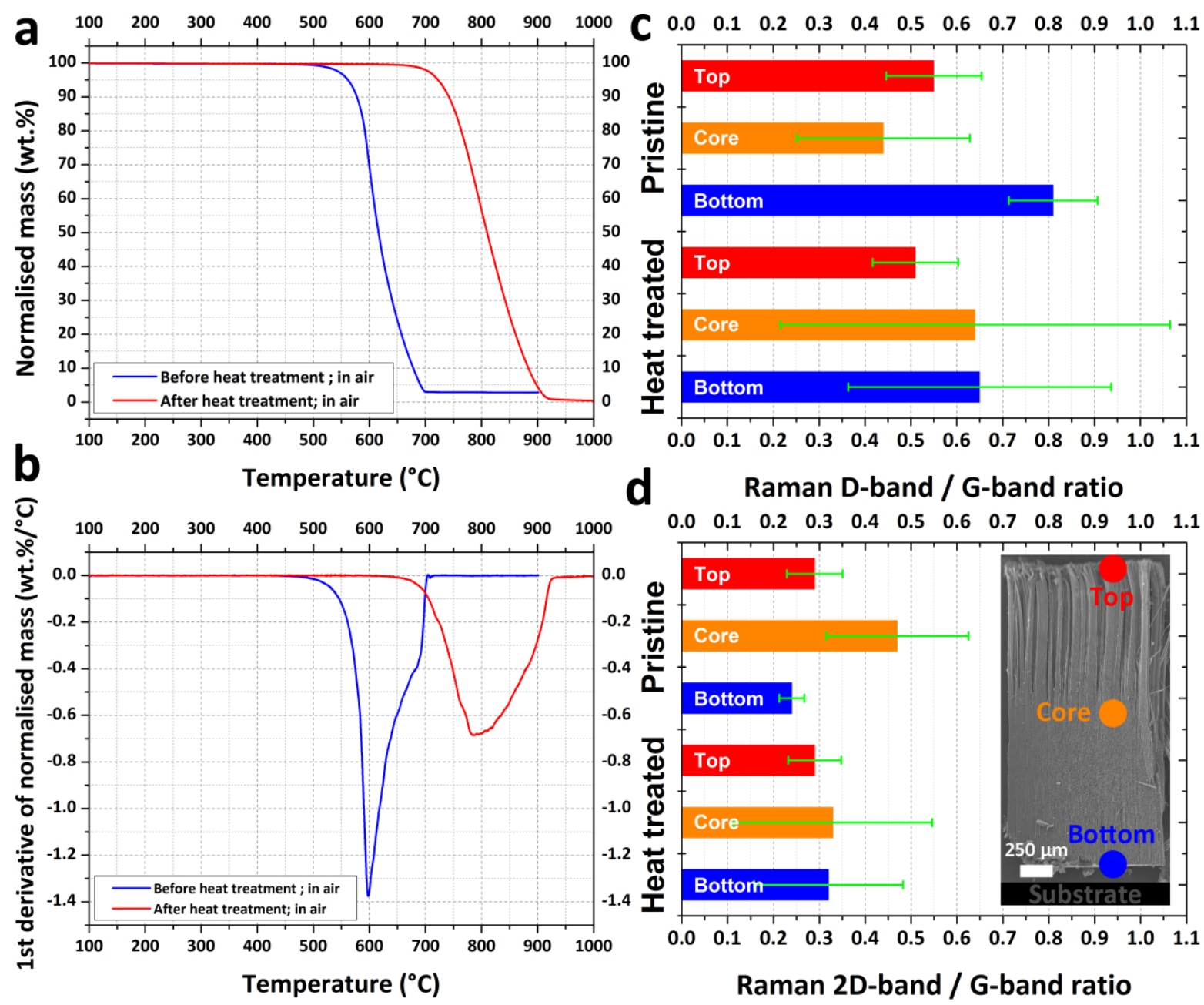


Figure 5. Oxidation resistance (a); oxidation rate (b); Raman D-band/G-band ratio (c) and

Raman 2D-band/G-band ratio (d) of pristine and heat-treated carpets of VA-MWCNTs.

Measurement of the compression modulus of carpets using nanoindentation revealed that the heat-treated carpets, on average, show higher compression elasticity. Although the results were fairly independent of the indentation depth, the bottom and top of the carpets exhibited completely different compression moduli. The moduli measured from the top of both pristine and heat-treated carpets were comparable to values in literature ${ }^{38,61,62}$ (figure 6). However, the moduli measured from the bottom of the carpets were almost an order of magnitude higher than previously reported. This increase is not due to the presence of the catalyst particles at the bottom of the carpets nor is related to the defect density of individual MWCNTs, because the catalyst-free heat-treated samples showed even higher moduli (up to $120 \mathrm{MPa}$ ) and according to Raman (figure 5c) MWCNTs are more defective at the bottom. Therefore, this increase is probably due to the fact that at the bottom of the carpets the arrangement of MWCNTs is denser, smoother, and hence, the resistance to indentation is higher. Since our measurements were carried out on free-standing carpets, we were able to measure the moduli on both sides of the carpet, compared to previous works which were performed on supported carpets. To the best of our knowledge, the compression moduli of the bottom of these carpets are the highest values reported so far for VA-MWCNTs. Considering the anisotropic nature of CNTs, It is noteworthy to mention that the geometry of the indentation tip, force, displacement speed, etc. could potentially have a significant impact on the reported moduli. Therefore, the current study preliminarily provides an indicative comparison of improved compression moduli over the values previously reported in literature. In this regard, a metrology study formulating a conversion table for translation of the compression moduli of VA-MWCNT carpets obtained from different indentation setups 
seems to be a necessary investigation for more accurate comparison of the moduli across the literature.

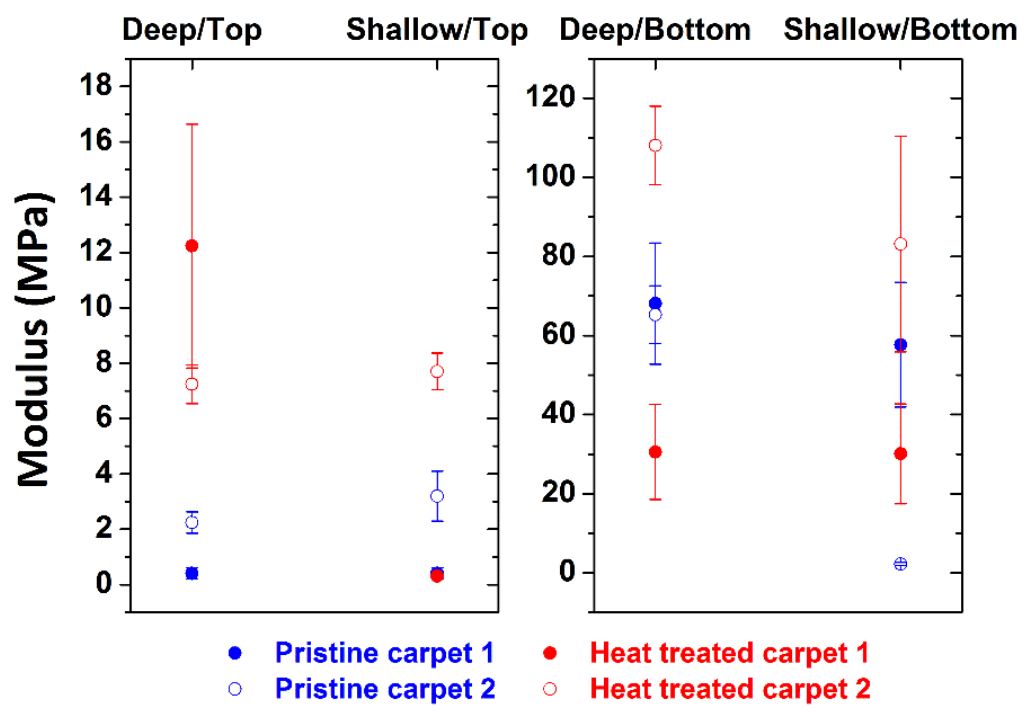

Figure 6. Compression moduli measured by nanoindentation on the bottom and top of the pristine and heat-treated carpets of VA-MWCNTs. 'Shallow' indentation: $5 \mu m$; 'Deep' indentation: $15 \mu \mathrm{m}$ (for representative original load-indentation graphs see figure SI5 in supplementary information).

\subsection{Plasma treatment of large-area carpets of ultra-long MWCNTs}

Development of graphite-element furnaces to anneal MWCNTs at temperatures beyond 3000 ${ }^{\circ} \mathrm{C}$ is demanding ${ }^{63,64}$. Alternatively, other sources of energy such as arc-discharge and laser could be considered to locally heat the carpets at temperatures as high as $10^{\prime} 000-20$ '000 K 65,66 .

In our case, arc-discharge was used for localised heating of VA-MWCNT carpets. Arcdischarge did not significantly alter the morphology of the portion of VA-MWCNT carpets wedged in the graphite anode, possibly because the carpets were not directly exposed to the arc, or because there is a significant temperature gradient even at short distances from the arc. On the other hand, the suspended carpets yielded a rather interesting composite consisting of 
graphite, CVD MWCNTs and arc-discharge-like CNTs ${ }^{67}$. The preliminary results are presented in the supplementary information.

\section{Conclusions}

Post-synthesis processing of free-standing large-area carpets of ultra-long MWCNTs was shown to favourably alter their microstructure and properties. Heat treatment of VAMWCNT carpets up to $2350{ }^{\circ} \mathrm{C}$ improved the overall sample purity and resulted in partial alignment of neighbouring crystallites only. It does, however, appear that full annealing of the material at nano and sub-nano scales, e.g. removal of point defects, is challenging. Nanoindentation on the VA-MWCNT carpets indicated a noticeable improvement in mechanical properties after heat treatment. However, it also showed that compression moduli of the bottom and top of the carpets (up to $100 \mathrm{MPa}$ ) varied significantly. This difference is not linked to the presence of catalyst particles or the defect density of individual tubes but it is due to the change in separation of the VA-MWCNTs at the root compared to the top surface. Exposure to arc-discharge plasma was found to largely transform the VA-MWCNTs into a novel carbon-carbon composite material which is of scientific interest in its own right, but beyond the scope of this present study. The development of processing procedures at higher thermal energies - than typical high-temperature furnaces provide - but less violent than plasma temperatures - to avoid evaporation and contamination - is essential to further improve the crystallinity and stiffness of the VA-MWCNT carpets and to exploit these in end-user applications.

\section{Acknowledgements}

The funding bodies who supported this work are European Commission's Seventh Framework Programme CONTACT and BioBone Marie Curie Initial Training Networks; Royal Society; European Research Council Starting Grant (ERC-2009-StG 240500 DEDIGROWTH); European Research Council Proof of Concept (ERC-2012-PoC309786 
DEVICE \& CONDUCT); the UK Government for Engineering and Physical Sciences

Research Council (EPSRC) for the fellowship programme 'Manufacturing the future: endohedral fullerenes, small molecules, big challenges' (EP/K030108/1), Pathways to Impact grants and Impact Acceleration Accounts.

\section{References}

1. Huard M, Roussel F, Rouzière S, Patel S, Pinault M, Mayne-L'Hermite M, et al. Vertically aligned carbon nanotube-based composite: Elaboration and monitoring of the nanotubes alignment. J Appl Polym Sci [Internet]. 2014;131(1):39730. Available from: http://dx.doi.org/10.1002/app.39730

2. Askari D, Ghasemi-Nejhad MN. Effects of vertically aligned carbon nanotubes on shear performance of laminated nanocomposite bonded joints. Sci Technol Adv Mater [Internet]. 2012;13(4):45002. Available from: http://stacks.iop.org/1468$6996 / 13 / \mathrm{i}=4 / \mathrm{a}=045002$

3. Allen RJ, Ghita O, Farmer B, Beard M, Evans KE. Mechanical testing and modelling of a vertically aligned carbon nanotube composite structure. Compos Sci Technol [Internet]. 2013;77(0):1-7. Available from: http://www.sciencedirect.com/science/article/pii/S0266353813000079

4. Zeng Y, Ci L, Carey BJ, Vajtai R, Ajayan PM. Design and Reinforcement: Vertically Aligned Carbon Nanotube-Based Sandwich Composites. ACS Nano [Internet]. American Chemical Society; 2010 Oct 19;4(11):6798-804. Available from: http://dx.doi.org/10.1021/nn101650p

5. Srivastava A, Srivastava ON, Talapatra S, Vajtai R, Ajayan PM. Carbon nanotube filters. Nat Mater [Internet]. Nature Publishing Group; 2004 Sep;3(9):610-4. Available from: http://dx.doi.org/10.1038/nmat1192

6. Du F, Qu L, Xia Z, Feng L, Dai L. Membranes of vertically aligned superlong carbon nanotubes. Langmuir [Internet]. $2011 \mathrm{Jul}$ 5;27(13):8437-43. Available from: http://www.ncbi.nlm.nih.gov/pubmed/21657212

7. Yu M, Funke HH, Falconer JL, Noble RD. High density, vertically-aligned carbon nanotube membranes. Nano Lett [Internet]. 2009 Jan;9(1):225-9. Available from: http://www.ncbi.nlm.nih.gov/pubmed/19099406

8. Yang HY, Han ZJ, Yu SF, Pey KL, Ostrikov K, Karnik R. Carbon nanotube membranes with ultrahigh specific adsorption capacity for water desalination and purification. Nat Commun [Internet]. 2013 Jan [cited 2014 Oct 12];4:2220. Available from: http://www.ncbi.nlm.nih.gov/pubmed/23941894

9. Tong T, Zhao Y, Delzeit L, Kashani A, Meyyappan M, Majumdar A. Dense Vertically Aligned Multiwalled Carbon Nanotube Arrays as Thermal Interface Materials. IEEE Trans Components Packag Technol [Internet]. 2007 Mar;30(1):92-100. Available from: http://ieeexplore.ieee.org/lpdocs/epic03/wrapper.htm?arnumber=4142686

10. Panzer M a., Zhang G, Mann D, Hu X, Pop E, Dai H, et al. Thermal Properties of Metal-Coated Vertically Aligned Single-Wall Nanotube Arrays. J Heat Transfer [Internet]. 2008 [cited 2014 Oct 23];130(5):052401. Available from: 
http://heattransfer.asmedigitalcollection.asme.org/article.aspx $?$ articleid=1474627

11. Huang H, Liu CH, Wu Y, Fan S. Aligned Carbon Nanotube Composite Films for Thermal Management. Adv Mater [Internet]. WILEY-VCH Verlag; 2005;17(13):1652-6. Available from: http://dx.doi.org/10.1002/adma.200500467

12. Tsai TY, Lee CY, Tai NH, Tuan WH. Transfer of patterned vertically aligned carbon nanotubes onto plastic substrates for flexible electronics and field emission devices. Appl Phys Lett [Internet]. 2009 [cited 2014 Oct 17];95(1):013107. Available from: http://scitation.aip.org/content/aip/journal/apl/95/1/10.1063/1.3167775

13. Hsia B, Marschewski J, Wang S, In J Bin, Carraro C, Poulikakos D, et al. Highly flexible, all solid-state micro-supercapacitors from vertically aligned carbon nanotubes. Nanotechnology [Internet]. 2014 Feb 7 [cited 2014 Oct 13];25(5):055401. Available from: http://www.ncbi.nlm.nih.gov/pubmed/24407158

14. Kim B, Chung H, Kim W. High-performance supercapacitors based on vertically aligned carbon nanotubes and nonaqueous electrolytes. Nanotechnology [Internet]. 2012 Apr 20 [cited 2014 Oct 23];23(15):155401. Available from: http://www.ncbi.nlm.nih.gov/pubmed/22437007

15. Azam M, Fujiwara A, Shimoda T. Significant capacitance performance of vertically aligned single-walled carbon nanotube supercapacitor by varying potassium hydroxide concentration. Int J Electrochem Sci [Internet]. 2013 [cited 2014 Nov 5];8(3):3902-11. Available from: http://www.electrochemsci.org/papers/vol8/80303902.pdf

16. Pint CL, Nicholas NW, Xu S, Sun Z, Tour JM, Schmidt HK, et al. Three dimensional solid-state supercapacitors from aligned single-walled carbon nanotube array templates. Carbon [Internet]. Elsevier Ltd; 2011 Nov [cited 2014 Oct 15];49(14):4890-7. Available from: http://linkinghub.elsevier.com/retrieve/pii/S0008622311005549

17. Ruoff RS, Qian D, Liu WK. Mechanical properties of carbon nanotubes: theoretical predictions and experimental measurements. Comptes Rendus Phys [Internet]. 2003 Nov [cited 2013 Mar 9];4(9):993-1008. Available from: http://linkinghub.elsevier.com/retrieve/pii/S1631070503001130

18. Salvetat J-P, Bonard J-M, Thomson NH, Kulik AJ, Forró L, Benoit W, et al. Mechanical properties of carbon nanotubes. Appl Phys A Mater Sci Process [Internet]. 1999 Sep 1;69(3):255-60. Available from: http://link.springer.com/10.1007/s003390050999

19. Demczyk BG, Wang YM, Cumings J, Hetman M, Han W, Zettl A, et al. Direct mechanical measurement of the tensile strength and elastic modulus of multiwalled carbon nanotubes. Mater Sci Eng A [Internet]. 2002 Sep 1;334(1-2):173-8. Available from: http://www.sciencedirect.com/science/article/pii/S092150930101807X

20. Ding W, Calabri L, Kohlhaas KM, Chen X, Dikin D a., Ruoff RS. Modulus, Fracture Strength, and Brittle vs. Plastic Response of the Outer Shell of Arc-grown Multiwalled Carbon Nanotubes. Exp Mech [Internet]. 2006 Aug 1 [cited 2013 Apr 27];47(1):25-36. Available from: http://link.springer.com/10.1007/s11340-006-9344-6

21. Lukić B, Seo JW, Couteau E, Lee K, Gradečak S, Berkecz R, et al. Elastic modulus of multi-walled carbon nanotubes produced by catalytic chemical vapour deposition. Appl Phys A [Internet]. 2004 Dec 15 [cited 2013 Aug 12];80(4):695-700. Available from: http://link.springer.com/10.1007/s00339-004-3100-5 
22. Guhados G, Wan W, Sun X, Hutter JL. Simultaneous measurement of Young's and shear moduli of multiwalled carbon nanotubes using atomic force microscopy. J Appl Phys [Internet]. AIP; 2007;101(3):33514. Available from:

http://link.aip.org/link/?JAP/101/033514/1

23. Peigney A. Composite materials: Tougher ceramics with nanotubes. Nat Mater [Internet]. Nature Publishing Group; 2003 Jan;2(1):15-6. Available from: http://dx.doi.org/10.1038/nmat794

24. Dalton AB, Collins S, Muñoz E, Razal JM, Ebron VH, Ferraris JP, et al. Super-tough carbon-nanotube fibres. Nature [Internet]. 2003 Jun 12;423(6941):703. Available from: http://www.ncbi.nlm.nih.gov/pubmed/12802323

25. Xia Z, Riester L, Curtin WA, Li H, Sheldon BW, Liang J, et al. Direct observation of toughening mechanisms in carbon nanotube ceramic matrix composites. Acta Mater [Internet]. 2004;52(4):931-44. Available from: http://www.sciencedirect.com/science/article/pii/S1359645403006608

26. Qian D, Dickey EC, Andrews R, Rantell T. Load transfer and deformation mechanisms in carbon nanotube-polystyrene composites. Appl Phys Lett [Internet]. 2000 [cited 2013 May 22];76(20):2868. Available from: http://scitation.aip.org/content/aip/journal/apl/76/20/10.1063/1.126500

27. Meysami SS. Development of an aerosol-CVD technique for the production of CNTs with integrated online control [Internet]. University of Oxford; 2013. Available from: http://ora.ox.ac.uk/objects/ora:7579

28. Meysami SS, Dillon F, Koós AA, Aslam Z, Grobert N. Aerosol-assisted chemical vapour deposition synthesis of multi-wall carbon nanotubes: I. Mapping the reactor. Carbon [Internet]. 2013 Jul;58:151-8. Available from: http://www.sciencedirect.com/science/article/pii/S0008622313001851

29. Meysami SS, Koós A a., Dillon F, Grobert N. Aerosol-assisted chemical vapour deposition synthesis of multi-wall carbon nanotubes: II. An analytical study. Carbon [Internet]. 2013 Jul [cited 2013 Jul 11];58:159-69. Available from: http://linkinghub.elsevier.com/retrieve/pii/S0008622313001826

30. Meysami SS, Koós A a, Dillon F, Dutta M, Grobert N. Aerosol-assisted chemical vapour deposition synthesis of multi-wall carbon nanotubes: III. Towards upscaling. Carbon [Internet]. $2015 \mathrm{Feb}$ [cited $2015 \mathrm{Feb} 24] ; 8: 148-56$. Available from: http://linkinghub.elsevier.com/retrieve/pii/S0008622315001335

31. Kim Y a., Muramatsu H, Hayashi T, Endo M, Terrones M, Dresselhaus MS. Thermal stability and structural changes of double-walled carbon nanotubes by heat treatment. Chem Phys Lett [Internet]. 2004 Nov [cited 2014 Oct 24];398(1-3):87-92. Available from: http://linkinghub.elsevier.com/retrieve/pii/S0009261404014095

32. Fujisawa K, Tojo T, Muramatsu H, Elías AL, Vega-Díaz SM, Tristán-López F, et al. Enhanced electrical conductivities of $\mathrm{N}$-doped carbon nanotubes by controlled heat treatment. Nanoscale [Internet]. 2011 Oct 5 [cited 2014 Nov 4];3(10):4359-64. Available from: http://www.ncbi.nlm.nih.gov/pubmed/21909584

33. Chen J, Shan JY, Tsukada T, Munekane F, Kuno A, Matsuo M, et al. The structural evolution of thin multi-walled carbon nanotubes during isothermal annealing. Carbon [Internet]. 2007 Feb [cited 2014 Nov 4];45(2):274-80. Available from: http://linkinghub.elsevier.com/retrieve/pii/S0008622306004933 
34. Andrews R, Jacques D, Qian D, Dickey EC. Purification and structural annealing of multiwalled carbon nanotubes at graphitization temperatures. Carbon [Internet]. 2001 Sep;39(11):1681-7. Available from:

http://linkinghub.elsevier.com/retrieve/pii/S0008622300003018

35. Endo M, Kim Y a., Fukai Y, Hayashi T, Terrones M, Terrones H, et al. Comparison study of semi-crystalline and highly crystalline multiwalled carbon nanotubes. Appl Phys Lett [Internet]. 2001 [cited 2014 Nov 4];79(10):1531. Available from: http://scitation.aip.org/content/aip/journal/apl/79/10/10.1063/1.1400774

36. Hou P-X, Liu C, Cheng H-M. Purification of carbon nanotubes. Carbon [Internet]. 2008 Dec [cited 2014 Jul 10];46(15):2003-25. Available from: http://linkinghub.elsevier.com/retrieve/pii/S000862230800448X

37. Boncel S, Koziol KKK. Enhanced graphitization of c-CVD grown multi-wall carbon nanotube arrays assisted by removal of encapsulated iron-based phases under thermal treatment in argon. Appl Surf Sci [Internet]. 2014 May [cited 2014 Nov 4];301:48891. Available from: http://www.sciencedirect.com/science/article/pii/S0169433214004127

38. Cao A, Dickrell PL, Sawyer WG, Ghasemi-Nejhad MN, Ajayan PM. Supercompressible foamlike carbon nanotube films. Science [Internet]. 2005 Nov 25 [cited 2014 Nov 5];310(5752):1307-10. Available from:

http://www.ncbi.nlm.nih.gov/pubmed/16311330

39. Ci L, Suhr J, Pushparaj V, Zhang X, Ajayan PM. Continuous carbon nanotube reinforced composites. Nano Lett [Internet]. 2008 Sep;8(9):2762-6. Available from: http://www.ncbi.nlm.nih.gov/pubmed/18680351

40. Suhr J, Victor P, Ci L, Sreekala S, Zhang X, Nalamasu O, et al. Fatigue resistance of aligned carbon nanotube arrays under cyclic compression. Nat Nanotechnol [Internet]. 2007 Jul [cited 2014 Nov 5];2(7):417-21. Available from: http://www.ncbi.nlm.nih.gov/pubmed/18654325

41. Ci L, Manikoth SM, Li X, Vajtai R, Ajayan PM. Ultrathick Freestanding Aligned Carbon Nanotube Films. Adv Mater [Internet]. 2007 Sep 25 [cited 2014 Oct 24];19(20):3300-3. Available from: http://doi.wiley.com/10.1002/adma.200602974

42. Huang J-Q, Zhang Q, Zhao M-Q, Wei F. The release of free standing verticallyaligned carbon nanotube arrays from a substrate using $\mathrm{CO} 2$ oxidation. Carbon [Internet]. 2010 Apr [cited 2014 Oct 24];48(5):1441-50. Available from: http://www.sciencedirect.com/science/article/pii/S0008622309008501

43. Boulanger P, Belkadi L, Descarpentries J, Porterat D, Hibert E, Brouzes A, et al. Towards large scale aligned carbon nanotube composites: an industrial safe-by-design and sustainable approach. J Phys Conf Ser [Internet]. 2013 Apr 10 [cited 2013 Apr 23];429:012050. Available from: http://stacks.iop.org/17426596/429/i=1/a=012050?key=crossref.d2bfe256952aa38bf35e40094342e4bb

44. Yasuda S, Futaba DN, Yamada T, Satou J, Shibuya A, Takai H, et al. Improved and large area single-walled carbon nanotube forest growth by controlling the gas flow direction. ACS Nano [Internet]. 2009 Dec 22;3(12):4164-70. Available from: http://www.ncbi.nlm.nih.gov/pubmed/19947579

45. Nicholls RJ, Britton J, Meysami SS, Koos AA, Grobert N. In situ engineering of NanoBud geometries. Chem Commun [Internet]. The Royal Society of Chemistry; 
2013;49(93):10956-8. Available from: http://dx.doi.org/10.1039/C3CC46064A

46. Oliver WC, Pharr GM. An improved technique for determining hardness and elastic modulus using load and displacement sensing indentation experiments. J Mater Res [Internet]. 1992;7(06):1564-83. Available from:

http://journals.cambridge.org/article_S0884291400017039

47. Franklin RE. Crystallite Growth in Graphitizing and Non-Graphitizing Carbons. Proc R Soc London Ser A Math Phys Sci [Internet]. 1951;209(1097):196-218. Available from: http://rspa.royalsocietypublishing.org/content/209/1097/196.abstract

48. Harris PJF. Rosalind Franklin's work on coal, carbon, and graphite. Interdiscip Sci Rev [Internet]. 2001;26(3):204-10. Available from: http://www.personal.rdg.ac.uk/ scsharip/REF_paper.pdf

49. Wu W, Jauregui LA, Su Z, Liu Z, Bao J, Chen YP, et al. Growth of Single Crystal Graphene Arrays by Locally Controlling Nucleation on Polycrystalline $\mathrm{Cu}$ Using Chemical Vapor Deposition. Adv Mater [Internet]. WILEY-VCH Verlag; 2011;23(42):4898-903. Available from: http://dx.doi.org/10.1002/adma.201102456

50. Wang H, Wang G, Bao P, Yang S, Zhu W, Xie X, et al. Controllable Synthesis of Submillimeter Single-Crystal Monolayer Graphene Domains on Copper Foils by Suppressing Nucleation. J Am Chem Soc [Internet]. 2012;134(8):3627-30. Available from: http://dx.doi.org/10.1021/ja2105976

51. Vlassiouk I, Smirnov S, Regmi M, Surwade SP, Srivastava N, Feenstra R, et al. Graphene Nucleation Density on Copper: Fundamental Role of Background Pressure. J Phys Chem C [Internet]. 2013;117(37):18919-26. Available from: http://dx.doi.org/10.1021/jp4047648

52. Yu Q, Jauregui LA, Wu W, Colby R, Tian J, Su Z, et al. Control and characterization of individual grains and grain boundaries in graphene grown by chemical vapour deposition. Nat Mater [Internet]. Nature Publishing Group; 2011 Jun;10(6):443-9. Available from: http://dx.doi.org/10.1038/nmat3010

53. Murdock AT, Koos A, Britton T Ben, Houben L, Batten T, Zhang T, et al. Controlling the Orientation, Edge Geometry, and Thickness of Chemical Vapor Deposition Graphene. ACS Nano [Internet]. 2013;7(2):1351-9. Available from: http://dx.doi.org/10.1021/nn3049297

54. Kim KSKS, Zhao Y, Jang H, Lee SY, Kim JM, Kim KSKS, et al. Large-scale pattern growth of graphene films for stretchable transparent electrodes. Nature [Internet]. Nature Publishing Group; 2009 Mar 5 [cited 2014 Apr 30];457(7230):706-10. Available from: http://www.ncbi.nlm.nih.gov/pubmed/19145232

55. Chae SJ, Güneş F, Kim KK, Kim ES, Han GH, Kim SM, et al. Synthesis of LargeArea Graphene Layers on Poly-Nickel Substrate by Chemical Vapor Deposition: Wrinkle Formation. Adv Mater [Internet]. 2009 Jun 12 [cited 2014 Nov 17];21(22):2328-33. Available from: http://doi.wiley.com/10.1002/adma.200803016

56. Feng X, Chee S, Sharma R, Liu K, Xie X, Li Q, et al. In Situ TEM observation of the gasification and growth of carbon nanotubes using iron catalysts. Nano Res [Internet]. Tsinghua Press; 2011;4(8):767-79. Available from: http://dx.doi.org/10.1007/s12274011-0133-x

57. Hofmann S, Sharma R, Ducati C, Du G, Mattevi C, Cepek C, et al. In situ Observations of Catalyst Dynamics during Surface-Bound Carbon Nanotube 
Nucleation. Nano Lett [Internet]. 2007;7(3):602-8. Available from: http://pubs.acs.org/doi/abs/10.1021/n10624824

58. Lin M, Tan JPY, Boothroyd C, Loh KP, Tok ES, Foo Y-L. Dynamical Observation of Bamboo-like Carbon Nanotube Growth. Nano Lett [Internet]. 2007;7(8):2234-8. Available from: http://pubs.acs.org/doi/abs/10.1021/n1070681x

59. Sharma R, Rez P, Treacy MMJ, Stuart SJ. In situ observation of the growth mechanisms of carbon nanotubes under diverse reaction conditions. J Electron Microsc (Tokyo) [Internet]. 2005;54(3):231-7. Available from:

http://jmicro.oxfordjournals.org/content/54/3/231.abstract

60. Yoshida H, Takeda S, Uchiyama T, Kohno H, Homma Y. Atomic-Scale In-situ Observation of Carbon Nanotube Growth from Solid State Iron Carbide Nanoparticles. Nano Lett [Internet]. 2008;8(7):2082-6. Available from:

http://pubs.acs.org/doi/abs/10.1021/n1080452q

61. Lu YC, Joseph J, Zhang Q, Maschmann MR, Dai L, Baur J. Large-Displacement Indentation Testing of Vertically Aligned Carbon Nanotube Arrays. Exp Mech [Internet]. 2012 Mar 27 [cited 2014 Dec 5];52(9):1551-4. Available from: http://link.springer.com/10.1007/s11340-012-9609-1

62. Tong T, Zhao Y, Delzeit L, Kashani A, Meyyappan M, Majumdar A. Height independent compressive modulus of vertically aligned carbon nanotube arrays. Nano Lett [Internet]. 2008 Feb;8(2):511-5. Available from: http://pubs.acs.org/doi/abs/10.1021/n1072709a

63. Marsh H, Wynne-Jones WFK. A high temperature $\left(3000^{\circ} \mathrm{C}\right)$ graphite furnace for laboratory use. J Sci Instrum [Internet]. 1965;42(9):710. Available from: http://stacks.iop.org/0950-7671/42/i=9/a=413

64. Abrahamson J. Graphite sublimation temperatures, carbon arcs and crystallite erosion. Carbon [Internet]. 1974 Apr;12(2):111-41. Available from: http://linkinghub.elsevier.com/retrieve/pii/0008622374900190

65. Glickstein S. Temperature measurements in a free burning arc. Weld J [Internet]. 1976 [cited 2014 Jul 23]; Available from: http://aws.org/wj/supplement/WJ_1976_08_s222.pdf

66. Haidar J, Farmer AJD. Temperature measurements for high-current free-burning arcs in nitrogen. J Phys D Appl Phys [Internet]. 1993;26(8):1224. Available from: http://stacks.iop.org/0022-3727/26/i=8/a=011

67. Dallas P, Meysami SS, Grobert N, Porfyrakis K. Classification of carbon nanostructure families occurring in a chemically activated arc discharge reaction. RSC Adv [Internet]. The Royal Society of Chemistry; 2016;6(30):24912-20. Available from: http://dx.doi.org/10.1039/C5RA26325E 